\title{
Bizarreness as a nonessential variable in mnemonic imagery: A confirmation
}

\author{
R. J. SENTER and ROBERT R. HOFFMAN \\ University of Cincinnati, Cincinnati, Ohio 45221
}

A positive replication of Wollen, Weber, and Lowry (1972) demonstrating that interactiveness appears to be more important than bizarreness in imaginal mnemonic learning is reported.

This paper reports a replication of Wollen, Weber, and Lowry (1972). The purpose of the Wollen et al. paper was to put to test the contention asserted by many commercial mnemonists, and some academic researchers (including the present senior author), that a quality called "bizarreness" (Persensky \& Senter, 1970a) is an important feature in the application of imaginal mnemonic procedures (Senter, 1971; Bower, 1970). The point of contention seemed to be whether "bizarreness" is a condition necessary to the storage of mnemonic mental images or whether what has been called "bizarreness" is an artifact resulting from confounding with the real effective characteristic, i.e., an "interactive" relationship between the elements stored in the mental image. In reviewing the Persenky and Senter $1970 \mathrm{a}$ article, we can find nothing indicating that a formal assertion that bizarreness is either a necessary or sufficient condition for imaginal mnemonic storage was ever made. We can understand, however, how such a contention might have been implied from the tone of the article and, it is admitted, that Persensky and Senter believed, at the time of writing the 1970a article, that bizarreness was a factor conducive to successful imaginal mnemonic learning. Since the Wollen et al. paper offered conclusions which took exception to our previous research, we were naturally interested in performing an amended replication of the study. The results of that replication are offered herein.

\section{METHOD}

The materials used in the present study were virtually identical to those used by Wollen et al.. for Keith Wollen kindly provided us with his original art work. The stimulus materials were line drawings depicting nine pairs of high-imagery nouns which ranged from 6.07 to 6.83 on the Paivio. Yuille, and Madigan (1968) I scale. Specifically, the pairs were piano-cigar, whale-cradle, ovenhammer. daffodil-table. window-iron, barrel-frog. skull-bottle. elephant-shoes, and microscope-lobster. These line drawings were made in four different ways: noninteracting-nonbizarre (NN). noninieracting-bizarre (NB), interacting-nonbizarre (IN), and interacting-bizarre (IB). (See Wollen et al. for drawings.) Basically the NN pictures showed the two objects side-by-side; the NB

For reprints, address R. J. Senter, Location 48, University of Cincinnati. Cincinnati. Ohio 45221. representations showed both objects side-by-side with each distorted in some extraordinary way (dancing piano emitting notes-cigar lit at both ends); IN pictures showed the objects interacting in some ordinary way (cigar on a piano); the IB representations showed an unusual interaction of the objects (piano smoking a cigar). Half of the present experiment constituted an exact replication of the Wollen et al. basic procedure in which four groups of introductory psychology students were presented, respectively, with the pictures representing one of the experimental drawing formats. Groups raning in size from 4-6 were run at a time using projected $35-\mathrm{mm}$ photographs of the original art, with the nouns printed at the bottom of each picture, using a 2-sec exposure and a 4-sec ISI (the Wollen et al. no-picture control and repaired conditions were not replicated). We added one more condition in which we replicated the entire procedure with a 6-sec exposure time. All subjects were told to use the pictures shown them to associate the items in each pair. Recall sessions consisted of a 2-sec presentation (via projector) of one of the nouns from each pair followed by a 4-sec blank period to allow time for the subjects to write the response members. A 55-sec interval was interposed between learning and recall sessions. After the recall session, a questionnaire was given to determine what method of memorization had been used for each pair. 160 subjects $(20 /$ cell) participated in the experiment. On the basis of the postexperimental questionnaire, however, the data for 60 subjects were eliminated because these subjects indicated that they did not use the images as a medium for remembering. Such a procedure is indicated by findings reported by Persensky and Senter (1970b).

\section{RESULTS}

The 100 subjects remaining after postexperimental screening provided data which were analyzed by a 2 (time) by 2 (bizarreness) by 2 (interactiveness) analysis of variance with unequal cell Ns (the least squares solution). An interesting finding tangential to the main purpose of the experiment was that a majority (44 out of 60) of the subjects whose data were cast out due to nonconformity to imagery instructions were in the noninteractive groups. Apparently the subjects in the interactive groups found it easier to use the images presented in their mnemonic storage and recall.

The basic data. in terms of number of items correctly recalled, are summarized in Table 1 along with the original Wollen et al. data, where appropriate. In general, the relative order of magnitude of the means computed in the present experiment (except NB) conform to those originally reported. The $F$ ratios calculated with the present data yield (where comparisons are appropriate) 
Table 1

Mean Number of Correct Responses for Each Experimental Treatment*

\begin{tabular}{|c|c|c|}
\hline Condition & $2 \mathrm{Sec}$ & $6 \mathrm{Sec}$ \\
\hline NN & $2.43 \quad(3.50)$ & 5.12 \\
\hline NB & $4.00(3.05)$ & 5.77 \\
\hline IN & $5.60(6.60)$ & 7.75 \\
\hline IB & $5.88 \quad(6.67)$ & 7.68 \\
\hline
\end{tabular}

${ }^{*}$ Figures in parentheses are those reported by Wollen et al.

inferences identical to those reported by Wollen et al. The $F$ ratios associated with the bizarreness dimension $(F=1.85,1 / 92)$ failed to reach a respectable rejection level $(\mathrm{p}<.25)$. The $F$ ratios associated with interactiveness $(F=28.78,1 / 92)$ and time $(F=22.16,1 / 92)$ both had associated $p$ levels less than .001 . Frankly, we expected that the additional 6-sec time classification would have the effect of producing a significant three-way interaction showing the combination of bizarreness and interactiveness to produce higher recall probability, providing that a 6 -sec exposure time was allowed for mnemonic storage. This expected interaction was not in evidence $(F<1.00)$. The remaining two-way interactions were also nonsignificant, with Time by Bizarreness and Bizarreness by Interactiveness both yielding Fs less than 1.00 and the remaining Time by Interactiveness term yielding $F=1.24(1 / 92$ n.s. $)$.

Examination of Table 1 also shows another point of concurrence between the two studies in the sriking similarity of the performance of subjects receiving the two interactive conditions (i.e., IN and IB).

\section{DISCUSSION}

The results of the present experiment are taken as being a substantial confirmation of the original Wollen, Weber, and Lowry report. Examination of the paper criticized by Wollen et al. (Persensky \& Senter, 1970a) shows that at that time the implicit, if not explicit. intention of the authors was to have their subjects interpret "bizarreness" as an unusual relationship between the objects comprising the members of the PA nouns. The single pictorial example cited, which was used as a prototype for those subjects was an artist's rendering of the pair "bun-football" which showed a football sandwich on a bun. Our sincere intention was to imply to the subjects that the element of bizarreness to be used in their mental images was to be achieved through unusual interactive relationships between the members of the PA items and not by grotesque distortion of the individual members. By doing this we were almost certainly guilty, as alleged by Wollen et al., of confounding interactiveness and bizarreness, for in the late 1960 s we almost implicitly equated bizarreness with some unusual interactive relationship.
In addition to the results offered by Wollen, Weber, and Lowry and our own positive replication thereof, there now exists other information questioning bizarreness as a useful quality in imaginal mnemonics. Nappe and Wollen (1973) have reported that bizarre images do not significantly reduce the probability of recall but do require more time to create; hence. they may be considered less efficient than plausible mental images in PA learning. Collyer. Jonides. and Bevan (1972) had previously shown that plausible images are superior to bizarre images in affecting the likelihood of recall of noun-verb-noun triplets but report no significant difference in the time required to compose these different imaginal formats

It would seem, then. that we were in error in instructing our subjects to form bizarre mental images in our 1970a experiment. We do not feel. however. that our methodological error detracts from the fact that our best group in the 1970a study correctly recalled a mean of 35 out of 50 PA response members after only one learning trial. In those early days of research with imaginal mnemonics. we thought that such a level of recall was rather remarkable and was. indeed. the most salient finding reported. With respect to this issue, our opinion is still unaltered.

In light of information now available. it would seem that what our methodological error did, if anything, was to depress our subjects" performance and that if we had substituted the words "plausible interactive" for "bizarre" in the image instructions used in the 1970a study (and. indeed. in most of our other mnemonics studies of the late 60s). our subjects might quite well have performed even better.

\section{REFERENCES}

Bower, G. H. Analysis of a mnemonic device. American Scientist, 1970, 58, 496-510.

Collyer, S. C., Jonides. J., \& Bevan, W. Images as memory aids: Is bizarreness helpful? American Journal of Psychology, 1972, 85, 31-38.

Nappe, G. W., \& Wollen, K. A. Effects of instructions to form common and bizarre mental images on retention. Journal of Experimental Psychology, 1973, 100, 6-8.

Paivio, A.. Yuille, J. C., \& Madigan, S. A. Concreteness, imagery, and meaningfulness values for 925 nouns. Journal of Experimental Psychology, 1968, 76 (Monograph Supplement 2).

Persensky, J. J., \& Senter, R. J. An investigation of "bizarre" imagery as a mnemonic device. Psychological Record, $1970,20,145-150$. (a)

Persensky, J. J.. \& Senter. R. J. The effect of subjects' conforming to mnemonic instructions. Psychological Record, 1970, 74, 15-20. (b)

SENTER, R. J. Review of mnemonics and mnemonotechnics for improved memory. In R. M. Stutz, W. N. Dember, and J. J. Jenkins (Eds.), Exploring behavior and experience: Readings in general psychology. Englewood Cliffs: Prentice Hall, 1971. Pp. 126-137.

Wollen, K. A., Weber, A., \& Lowry, D. H. Bizarreness versus interaction of mental images as determinants of learning. Cognitive Psychology, 1972, 3, 518-523.

(Received for publication October 22, 1975.) 